Andrews University

Digital Commons @ Andrews University

Faculty Publications

$1-1-2011$

\title{
The Love of Money is the Root of all Evil: Pay Satisfaction and CPI as Moderators
}

\author{
Thomas Li Ping Tang \\ Middle Tennessee State University \\ Toto Sutarso \\ Middle Tennessee State University \\ Mahfooz A. Ansari \\ University of Lethbridge \\ Vivien Kim Geok Lim \\ National University of Singapore \\ Thompson Sian Hin Teo \\ National University of Singapore \\ Follow this and additional works at: https://digitalcommons.andrews.edu/pubs \\ see Partextpage Pernedititiondafautpors
}

\section{Recommended Citation}

Tang, Thomas Li Ping; Sutarso, Toto; Ansari, Mahfooz A.; Lim, Vivien Kim Geok; Teo, Thompson Sian Hin; Arias-Galicia, Fernando; Garber, llya; Vlerick, Peter; Liang, Jian; Akande, Adebowale; Allen, Michael W.; Alzubaidi, Abdulgawi Salim; Borg, Mark G.; Charles-Pauvers, Brigitte; Cheng, Bor Shiuan; Chiu, Randy K.; Du, Linzhi; De La Torre, Consuelo Garcia; Higgs, Rosario Correia; Ibrahim, Abdul Hamid Safwat; Jen, Chin Kang; Kazem, Ali Mahdi; Kim, Kilsun; Luna-Arocas, Roberto; Malovics, Eva; Moreira, Alice S.; Mpoyi, Richard T.; Nnedum, Anthony Ugochukwu Obiajulu; Osagie, Johnsto E.; Osman-Gani, Aahad M.; Özbek, Mehmet Ferhat; and Stembridge, Allen F., "The Love of Money is the Root of all Evil: Pay Satisfaction and CPI as Moderators" (2011). Faculty Publications. 1721.

https://digitalcommons.andrews.edu/pubs/1721

This Conference Proceeding is brought to you for free and open access by Digital Commons @ Andrews University. It has been accepted for inclusion in Faculty Publications by an authorized administrator of Digital Commons @ Andrews University. For more information, please contact repository@andrews.edu. 


\section{Authors}

Thomas Li Ping Tang, Toto Sutarso, Mahfooz A. Ansari, Vivien Kim Geok Lim, Thompson Sian Hin Teo, Fernando Arias-Galicia, llya Garber, Peter Vlerick, Jian Liang, Adebowale Akande, Michael W. Allen, Abdulgawi Salim Alzubaidi, Mark G. Borg, Brigitte Charles-Pauvers, Bor Shiuan Cheng, Randy K. Chiu, Linzhi Du, Consuelo Garcia De La Torre, Rosario Correia Higgs, Abdul Hamid Safwat Ibrahim, Chin Kang Jen, Ali Mahdi Kazem, Kilsun Kim, Roberto Luna-Arocas, Eva Malovics, Alice S. Moreira, Richard T. Mpoyi, Anthony Ugochukwu Obiajulu Nnedum, Johnsto E. Osagie, Aahad M. Osman-Gani, Mehmet Ferhat Özbek, and Allen F. Stembridge 


\title{
THE LOVE OF MONEY IS THE ROOT OF ALL EVIL: PAY SATISFACTION AND CPI AS MODERATORS
}

\author{
THOMAS LI-PING TANG \\ Jennings A. Jones College of Business \\ Middle Tennessee State University \\ Murfreesboro, TN 37132
}

TOTO SUTARSO, Middle Tennessee State University

MAHFOOZ A. ANSARI, University of Lethbridge

VIVIEN KIM GEOK LIM, National University of Singapore

THOMPSON SIAN HIN TEO, National University of Singapore

FERNANDO ARIAS-GALICIA, Universidad Autónoma del Estado de Morelos

ILYA GARBER, Saratov State University

PETER VLERICK, Ghent University

JIAN LIANG, Shanghai Jiao Tong University

ADEBOWALE AKANDE, Potchefstroom University

MICHAEL W. ALLEN, University of Sydney

ABDULGAWI SALIM ALZUBAIDI, Sultan Qaboos University

MARK G. BORG, University of Malta

BRIGITTE CHARLES-PAUVERS, University of Nantes

BOR-SHIUAN CHENG, National Taiwan University

RANDY K. CHIU, Hong Kong Baptist University

LINZHI DU, Nankai University

CONSUELO GARCIA DE LA TORRE, Technological Institute of Monterrey

ROSARIO CORREIA HIGGS, Polytechnic Institute of Lisbon-Portugal

ABDUL HAMID SAFWAT IBRAHIM, Iman University

CHIN-KANG JEN, National Sun-Yat-Sen University

ALI MAHDI KAZEM, Sultan Qaboos University

KILSUN KIM, Sogang University

ROBERTO LUNA-AROCAS, University of Valencia

EVA MALOVICS, University of Szeged

ALICE S. MOREIRA, Federal University of Pará

RICHARD T. MPOYI, Middle Tennessee State University

ANTHONY UGOCHUKWU OBIAJULU NNEDUM, Nnamdi Azikiwe University

JOHNSTO E. OSAGIE, Florida A \& M University

AAHAD M. OSMAN-GANI, UIA International University of Malaysia

MEHMET FERHAT ÖZBEK, University of Gumushane

FRANCISCO COSTA PEREIRA, Polytechnic Institute of Lisbon-Portugal

RUJA PHOLSWARD, Rangsit University

HORIA D. PITARIU, Babes-Bolyai University

MARKO POLIC, University of Ljubljana

ELISAVETA GJORGJI SARDŽOSKA, University St. Cyril and Methodius

PETAR SKOBIC, Middle Tennessee State University

ALLEN F. STEMBRIDGE, Andrews University

THERESA LI-NA TANG, Tang Global Consulting Group 
MARTINA TRONTELJ, University of Ljubljana

CAROLINE URBAIN, University of Nantes

LUIGINA CANOVA, University of Padua

ANNA MARIA MANGANELLI, University of Padua

\section{INTRODUCTION}

Corruption, defined as the illicit use of one's position or power for perceived personal or collective gain, is both a state and a process that reflects not only the corrupt behavior of an individual but also the dangerous, viruslike infection of a group, organization, industry, nation, or geopolitical entity (Ashforth, Gioia, Robinson, \& Treviño, 2008; Tepper, Carr, Breaux, Geider, Hu, \& Hua, 2009). It is a multilevel real-world phenomenon, directly or indirectly, related to money (Hitt, Beamish, Jackson, \& Mathieu, 2007; Kish-Gephart, Harrison, \& Treviño, 2010). Money is universally accepted across cultures; however, the meaning of money (Colquitt, LePine, \& Wesson, 2011) is in the eye of beholder (McClelland, 1967). Very little research has tested the validity of this oft-cited proposition empirically in a large scale cross-cultural studythe love of money is the root of all evil (Tang \& Chiu, 2003; Tang \& Chen, 2008).

Following the theory of planned behavior (TPB) (Ajzen, 1991), we investigate the relationship between attitude (love of money) and behavioral intention (work-related corrupt intent) in this study. Further, the justice literature suggests that perceptions of inequity provoke dishonesty, theft, or corruption (Cohen-Charash \& Spector, 2001; Gino \& Pierce, 2009; Greenberg, 1993, 2002; Huseman, Hatfield, Miles, 1987). Pay satisfaction (Heneman \& Judge, 2000) reflects perception of one's pay equity and distributive justice. Following the adage, "whoever loves money is never satisfied with his or her income" (Tang et al., 2006), we assert that pay satisfaction moderates the love of money to work-related corrupt intent relationship.

The person-situation interactionist model of ethical decision-making (Kish-Gephart et al., 2010; Rousseau \& Fried, 2001; Treviño, 1986) suggests that most people look to the social context to determine what is ethically right and wrong (Bandura, 1986), obey authority figures (Litzky, Eddleston, \& Kidder, 2006; Milgram, 1974) and laws, and do what is rewarded. We expand TPB (Ajzen, 1991) and treat Transparency International's Corruption Perceptions Index, CPI, a prevalent subjective social norm (Ajzen, 1991), as a proxy of a good/bad barrel at the entity/country level (Martin \& Cullen, 2006; Victor \& Cullen, 1988). We argue that the moderating role of pay satisfaction varies across levels of CPI.

In summary, we investigate the relationship between love of money and corrupt intent (one aspect of evil) by incorporating pay satisfaction at Level 1 and CPI at Level 2 and develop a multi-level theory of corruption in this study (Ashforth et al., 2008; Tepper et al., 2009). We posit a significant cross-level, three-way interaction effect of love of money, pay satisfaction, and CPI on work-related corrupt intent and test this theoretical model in a large cross-cultural study. We present our hypotheses below:

Hypothesis 1: There is a significant cross-level, three-way interaction effect.

Hypothesis 1a: Managers with high love of money and high pay satisfaction in low CPI entities have the highest magnitude of work-related corrupt intent; whereas those with low love of money and high pay satisfaction in high CPI entities have the lowest. Hypothesis 1b: The intensity of the relationship between love of money and work-related corrupt intent is stronger for managers with low pay satisfaction in the high CPI group than those with low pay satisfaction in the low CPI group. 


\section{METHODS}

\section{Sample and Procedure}

Collaborators adopted the English survey or translated it into their native language using the multistage translation/back-translation procedure (Brislin, 1980) and collected data in a single or multiple cities in both public and private sectors. Participants completed the surveys voluntarily, anonymously. The return rate varied between $45 \%$ and $100 \%$. We collected data from 6,586 managers (Level 1) in 32 geopolitical entities (Level 2) across six continents. For the present study, we deleted the Italian sample with missing variables and used data from a sample of 6,382 managers (Level 1) in 31 geopolitical entities (Level 2) across six continents. Managers were 34.66 years old, 50.6 percent male, with 15.35 years of education, and an average income of US\$14,199.15. The average sample size was 205.9 per entity/country.

\section{Measures}

We selected the 12-item, 4-factor Love of Money Scale (Tang \& Chiu, 2003) with Factors Rich, Motivator, Importance, and Power. We employed a 5-point Likert scale with the following anchors: strongly disagree (1), disagree (2), neutral (3), agree (4), and strongly agree (5). We adopted 18-item, 4-factor Pay Satisfaction Questionnaire with Factors Pay Level, Raises, Benefits, and Pay Administration (Heneman \& Schwab, 1985) and the following anchors: strongly dissatisfied (1), dissatisfied (2), neutral (3), satisfied (4), and strongly satisfied (5). We included a 7-item Work-related Corrupt Intent Scale (Sardžoska \& Tang, 2011; Tang \& Chiu, 2003; Tang \& Tang, 2010) using the following anchors: very low probability (1), low probability (2), average (3), high probability (4), and very high probability (5). We used three different scale anchors for these measures to deliberately avoid common method bias (Podsakoff, MacKenzie, Lee, \& Podsakoff, 2003). Among several indices related to ethical values/cultures in different entities (Corruption Perceptions Index (CPI), the Bribe Payers' Index, the Global Corruption Barometer, Global Corruption Report (Global Index of Bribery) and the World Values Survey), we selected CPI due to our large sample size at the entity level $(N=31)$. A high CPI score signifies low corruption.

\section{RESULTS}

We found a good fit between our measurement model and our data for our love of money, pay satisfaction, and corrupt intent scales using the whole sample and achieved configural and metric invariance for these measures across three CPI groups: High CPI (CPI $\geq$ 5.5, $n=2,761$ : Australia, Belgium, France, Hong Kong, Malta, Oman, Portugal, Singapore, Slovenia, Spain, Taiwan, and the USA), Medium CPI (5.5 > CPI > 3.5, $n=1,269$ : Brazil, Bulgaria, Hungary, Malaysia, South Africa, South Korea, and Thailand); and Low CPI (3.5 $\geq$ CPI, $n=2,352$ : China, Croatia, Congo, Egypt, Macedonia, Mexico, Nigeria, Peru, the Philippines, Romania, Russia, and Turkey). We examined the common method variance (CMV) in two steps (Podsakoff et al., 2003). First, Harman's single-factor test examines the unrotated factor solution involving all items of interest in an exploratory factor analysis (EFA). Results showed eight factors with eigenvalues greater than one. Second, the measurement model with the addition of an unmeasured latent common method variance (CMV) factor did not improve the fit 
over our measurement model without a CMV factor. Thus, the common method variance (CMV) was not a concern in this study. We test our theoretical model below.

We employed Mplus (Muthén \& Muthén, 2010, Version 6) for our cross-level analysis. In our within-level analysis, we used love of money and pay satisfaction to predict corrupt intent (Level 1). The between-level variable was CPI (Level 2). The random slope S1 was defined by the linear regression of corrupt intent on the interaction effect between love of money and pay satisfaction. We regressed S1 on CPI in our between-level analysis. Our cross-level, three-way interaction effect on corrupt intent was significant $(-2.61, p<.01)$, supporting Hypothesis 1 . Following Aiken and West (1991) and Dawson and Richter (2006), we plotted four slopes for the three-way interaction effect and compared six pairs of slopes using $t$ tests.

We labeled Slope 1 as managers with high pay satisfaction in high CPI entities and Slope 2 as those with high pay satisfaction in low CPI entities. For Slope 1, managers with low love of money had the lowest magnitude of corrupt intent (good apples). For Slope 2, those with high love of money had the highest magnitude of corrupt intent (bad apples), supporting Hypothesis 1a. Further, we labeled Slope 3 as managers with low pay satisfaction in high CPI group and Slope 4 as those with low pay satisfaction in low CPI group. Slope 3 showed the strongest intensity whereas Slope 4 had the weakest and the difference between the two was significant $(t$ $=3.09, p<.01$ ), supporting Hypothesis $1 \mathrm{~b}$. For those with high pay satisfaction, the intensity of the relationship between love of money and corrupt intent was almost identical regardless of whether they were in the low or the high CPI entities (Slope 1 vs. Slope $2: t=.31, p>.05$ ). There were no significant differences between Slopes 1 and $4(t=1.81, p>.05)$, between Slopes 2 and $4(t=1.63, p>.05)$, between Slopes 2 and 3, and between Slopes 1 and 3.

\section{DISCUSSION}

Theoretical Implications. The relationship between love of money and work-related corrupt intent is moderated by pay satisfaction at the micro level and CPI at the macro level, supporting and expanding the interactionist theory of ethical decision making (Kish-Gephart et al., 2010) and theory of planned behavior (Ajzen, 1991). Love of money (attitude) is significantly related to corrupt intent (behavioral intention) (Ajzen, 1991; Grant, 2008; Tang \& Baumeister, 1984). With "high pay satisfaction", the intensity (slope) for the relationship between love of money and corrupt intent is almost identical for managers in high or low CPI entities. The magnitude (intercept) of work-related corrupt intent for high or low CPI groups is significantly different. The former (high pay satisfaction and high CPI) has the lowest magnitude, whereas the latter (high pay satisfaction and low CPI) has the highest. As expected, managers in high CPI countries/entities have lower work-related corrupt intent than those in low CPI entities. Thus, CPI is a strong moderator.

In the high CPI entities (good barrels), high pay satisfaction enhances integrity and curbs corruption because a satisfied need is no longer a motivator (Maslow, 1954). The cost of corruption is too high for the benefit (Tepper et al., 2007). Managers do not want to take the risks and lose their freedom, dignity, integrity, and reputation in their lives (Gomez-Mejia et al., 2005). However, for people with high pay satisfaction in the low CPI entities (bad barrels), love of money fuels the corruption fire (Grant, 2008) causing them to have the highest magnitude of corrupt intent in this study. Bribery accounted for at least 20 percent of the total wage compensation in the public sector (Lambsdorff, 1999; McCarthy \& Puffer, 2008). We speculate that managers with high pay satisfaction (money earned legally or illegally) take corruption for 
granted, have the strongest winner-take-all mentality (the Matthew Effect; Merton, 1968; Tang, 1996), and consider corruption as an entitlement. Since money is an addictive, insatiable drug (Lea \& Webley, 2006), they need larger dosages to maintain the same level of "high" or utility of money and want more money after becoming members of the kleptocractic class (Grossman, 1999). Thus, bad apples appear by the bushel in bad barrels (Pinto, Leana, \& Pil, 2008). Due to meager resources, they may have nothing to lose and ignore the risks of loosing their freedom, dignity, integrity, and reputation. Even incarcerated, some may live comfortable with all the luxuries because money talks in a corrupted environment.

The intensity of the relationship between love of money and work-related corrupt intent for managers with low pay satisfaction in the high CPI group is significantly stronger than that in the low CPI group. Pay satisfaction matters more in high CPI entities than in low CPI entities. Low pay satisfaction in high CPI entities greatly enhances managers' intensity of corrupt intent due to their higher sensitivity to pay equity and justice (Huseman et al., 1987). Results support the justice literature that with perceptions of injustice, people will steal in the name of justice (Gino \& Pierce, 2009; Greenberg, 1993). We speculate that in a corrupt culture, the notion of equity or justice may or may not be highly valued as those managers in high CPI entities. With scarce resources and income, managers with low pay satisfaction in low CPI entities may have missed the opportunity for becoming a member of "the good ole boys club", or kleptocracy (rule by thieves, Grossman, 1999) due to the lack of resources (position, power, personal contact, and public visibility). They have low sensitivity to inequity and very little "hope" for justice. As a consequence, they develop the "learned helplessness" in that environment (Abramson, Seligman, $\&$ Teasdale, 1978). They have high magnitude but low intensity of corrupt intent because they do not do it for the love of money. Finally, we conclude that pay satisfaction is a double-edged sword with both positive and negative consequences. The impact of pay satisfaction on corruption may vary across high or low CPI entities. In summary, our research reveals (1) the relationship between love of money and work-related corrupt intent supporting the attitude-tobehavioral-intent aspect of TPB, (2) the importance of incorporating pay satisfaction at the micro level from the justice literature into TPB, (3) the value of integrating CPI, a subjective social norm, or contextual variable at the macro level (Kish-Gephart et al., 2010; Treviño, 1986) into TPB, (4) the expansion of TPB from an individual-level theory to a multi-level theory, (5) an easy way to tease out good and bad apples' unseen behavioral patterns in good or bad barrels and make them clearly visible in a new perspective, (6) identify not only contributions but boundaries of several theories (Ajzen, 1991; Ashforth et al., 2008; Herzberg, 1987; Milkovich et al., 2011).

Empirical Contributions. We incorporate pay satisfaction and CPI in our understanding of love of money to corrupt intent relationship based on a large sample of 6,382 managers in 31 geopolitical entities across six continents. Results regarding measurement models for the whole sample and measurement invariance across three CPI groups enhance the generalizability of our findings and offer confidence to future researchers in using these scales in underresearched areas of the world (Kirkman \& Law, 2005). Our counterintuitive discoveries (Bartunek, Rynes, \& Ireland, 2006) are impossible to achieve without a large sample size at both Level 1 and Level 2.

Practical Implications. Our results support the notion that the love of money is related to corrupt intent. Although it is difficult to manage managers' love of money because people bring dispositional values to organizations (Staw, Bell, \& Clausen, 1986), executives can still properly 
manage it in organizations. People need money (a hygiene factor) continuously to maintain their lives (Herzberg, 1987). "People do work for money-but they work even more for meaning in their lives" (Pfeffer, 1998: 112). Executives have strong control over their malleable compensation systems and can pay managers fairly and well. Managers with high pay satisfaction have a sense of self-sufficiency (Vohs, Mead, \& Goode, 2006), take their minds off money (Kohn, 1993), elevate their virtue and wisdom, inculcate their stewardship behaviors, and supplant opportunism and self-interest (Gomez-Mejia et al., 2005). Objective income, financial experiences, and ethical cultural values may shape or modify one's love of money and behavior.

Tang et al. (2011) also found that managers in low CPI entities with low corporate ethical values (CEV) have the highest magnitude (intercept) of corrupt intent, whereas those in high CPI entities with high CEV have the lowest. People in "high CPI entities with low CEV" or in "low CPI entities with high CEV" have almost identical intensity and magnitude of corrupt intent. Furthermore, the intensity between love of money and corrupt intent is the strongest for managers in "high CPI entities with low CEV" and the weakest for those in low CPI entities with low CEV. Top executives in high CPI entities with low pay satisfaction and low corporate ethical values $(\mathrm{CEV})$ may have not only the strongest intensity but also the highest magnitude of corruption and engage in grand corruption (kleptocracy). As Ariely pointed out that "when cheating is one step removed from cash", people tend to rationalize and justify their dishonesty easily. "Such latitude is the force behind the Enrons of the world" (2008: 24). Regardless of CPI, increasing corporate ethical values in organizations may also greatly reduce corruption because most people do want to receive reward and avoid punishment in the social context (Fisman \& Miguel, 2007). Executives have more control over corporate ethical values than the CPI (entity level). We assert that ethical values are both important at the organization and entity levels.

Conclusion. In order to eradicate corruption, boost business ethics globally, and maintain sustainable development in the competitive market, executives must implement an effective and efficient compensation system to cultivate a sense of justice, manage all stakeholders fairly and well, monitor love of money, pay satisfaction, firm-level pressures (Martin et al., 2007), and different forms of temptations across borders; valorize corporate ethical values; and inspire personal integrity (Feiner, 2004; Simons, 2002), implement organizational corruption control elements - bureaucratic control, punishment, incentive alignments, legal/regulatory sanctioning, social sanctioning, vigilance controls, self-control, and concertive controls (Lange, 2008), and fully aware of the contextual environment at micro and macro levels under which they operate. Although it pays to enhance managers' pay satisfaction and curb corruption, in general, our present finding challenges the assumptions that (1) the relationship between love of money and corrupt intent is the same across cultures, (2) high pay satisfaction is a good and important goal to pursue for all people around the world, and (3) the moderating effect of pay satisfaction on the love of money to corrupt intent relationship is the same across levels of CPI. Our research offers a new and robust theory that captures the complexity of organizational phenomena and realworld relevance in the field of management (Bamberger, 2008). We trust that our results provide a new perspective on behavioral ethics, relate to the globalization of the economy and internalization of management research, promote theory development and testing, and further research and improved practice (Colquitt \& Zapata-Phelan, 2007).

\section{REFERENCES AVAILABLE FROM THE AUTHORS}

